\title{
TEACHING THE GENERATION Z
}

\author{
Hristo Chukurliev, New Bulgarian University, Bulgaria
}

\section{Abstract}

The article presents the experience of New Bulgarian University to create a training program for its academic staff to resume bilateral communication with students born after 2000. It examines the alienation of the faculty from the students due to digital technologies and the change in the perception of knowledge as a value and access to information. It presents results of a survey of the professors' opinion and presents a structure of a training program.

\section{Introduction}

One of the main characters of the Generation $\mathrm{Z}$ is that it has been using the Internet from a very early age and has been working well with technology and social media. Other distinction is that this is the generation for which the internet is given. Thanks to the internet and the smart devices to access it, as well as with the help of search engines and Wikipedia, this is the generation for which information and knowledge are being pushed apart. Have you tried to give your students a task to find information about something and to see how much shorter time they need compared to you?! It's impressive.

I recently had a case with a distance learning student who asked me two and a half days before the deadline for submitting coursework on "Civilizations and Religions" to give her a topic to write about. Annoyed I search what the available materials in Bulgarian were on the theme "Mythology and religion of the Hittites" (I did, as I imagined what the student would have done), finding that they were scarce, sent the topic and asked the usual volume and text requirements. I put a control question - to make a comparison of the religion of the Hittites with that of the Slavs - in order to force student to develop the information gathered and presented in knowledge. I was confident that the student would fail in the task. As you guess, I received the work on time, even a few hours before the deadline. It was in full volume and with impressive and comprehensive information gathered and presented on religious and mythological systems of the Hittites and Slavs. There is no way to find out what happened. Whether it was translated by automatic text from another language and then carefully corrected or a search engine was used to reach a paper that I could not find. There was, however, one thing that was repeated with both this student and almost all of whom I had given a different subject for this semester and directly encouraged to use copy/paste from Internet, Wikipedia, etc. The information was gathered accurately, thoroughly and in detail. However, almost no one was able to answer the control question. The Hittites and Slavs student had read a great deal of facts, but she had not been able to compare them. 


\section{The broken communication with the Millennials}

There is a distance between us and our students in their favour in terms of using technology and the Internet as means of completing immediate tasks. Learning how to do something, buying something, understanding what is something and what to do with it. However, this "information" does not turn necessarily into knowledge.

I'm far from the idea of blame someone. On the contrary, I want the communication and socialization between me and the students, my colleagues and their students to resume. Our students are more withdrawn than self-sufficient. Unlike us who are set to change, riot, break with the previous generation, they have no sense of such a need. On the contrary, they are willing to share our views, but rather because they do not understand them and intuitively use them to build around their lives.

According to Bernard Toussaint, communication as an element of meta-language is: "Creating encrypted relations between the speaker and the listener, provided that the listener can turn into a speaker". With the Generation $\mathrm{Z}$ we seem to have no communication. The rules of communication require the message to be personal, to present facts, to be concrete, to be possible to ask questions, questions to be heard and to monitor body language. We are unable to adapt these rules to the $\mathrm{Z}$ Generation and the communication is virtually absent.

\section{Teaching teachers how to teach}

The need for action to overcome this gap between us and our students is obvious. For years, the results of the semester surveys for our students' satisfaction with a teacher, course and program have been problematic for use. It is increasingly difficult to motivate students to participate. The poll is in electronic form and students complete it at the end of the semester until the second week of the session. It visualizes to them as a dialog box in the e-learning platform, which they can minimize or just close. As a result, it reaches less than $10 \%$ participation. Perhaps we do not ask the right questions or worse, our students do not think that their answers will follow change and action. We are working on this issue, but this is another topic.

We needed to get to the names of those teachers whom the Generation $\mathrm{Z}$ liked. We crosschecked the information. We have selected the teachers permanently having high score most of the time. There were about 40 names out of a total of 446 full-time lecturers or $9 \%$. In another survey among all the lecturers, we asked few questions to identify a group of them willing to change. Out of the same group of 446,124 responded or $28 \%$. We compared the names of the 40 "high ranked" professors with those with willingness to change. As expected, they were in the group. So we came to the conclusion that we can invite these 40 lecturers to a series of interviews. We asked them what were their practices they thought made them successful with the students of the Z Generation. 20 of them responded or $4.5 \%$ out of the 446 initial sample. 
I believe that this low rate is one of the proofs that we used reliable methodology and we are on the right track.

We divided the 40 high ranked by the students' lecturers into 6 groups. We have separated as groups the lecturers from the fields of Law and Psychology. The other four groups were: Arts; Economics and Administration; Humanities and Social Sciences; Technical Sciences and Architecture. We did this in order not to mix groups of teachers with different profiles and specifics in teaching.

From these interviews, we found two facts that stand out. The teachers were well aware of and clearly shared what in their teaching is more special and appealing to the students. Along with that the teachers needed an environment and a situation where they could share the methods they use to get feedback and support from their colleagues and also to borrow good practices.

\section{The skeleton of the teaching program}

From the collected information from the interviews we were able to distinguish 5 specific problems:

\section{Motivation for learning}

Teachers are finding it increasingly difficult to keep student's attention on the material taught. The reasons for this lack of motivation for learning are different.

Most of the high scored teachers indicated that in their introductory lecture they clarified what would be studied in their course, why and for what purpose. Information is not knowledge, and lecturers explain to their students their role as mediators in this process of turning information into knowledge.

\section{Visual information}

Classical linear text is increasingly difficult to understand for students as a source of information.

The use of presentations with rich illustrative material is the most commonly used mean to overcome this deficiency. At the same time, lecturers break their lectures by projecting short videos on critical topics of the material. They use mostly documentaries from YouTube and also they produce some by themselves more and more.

\section{Theory vs. Practice}

Universities are increasingly preparing their students for the labour market rather than teaching pure science.

Teachers have found that practical training in a real work environment is particularly important. As some of our teachers are real life practitioners they integrate their students into their work. The others create simulations and invent games in which students practice their knowledge. Some of the teachers are critical and restrictive about smartphones by limiting 
their use in class. Others have realized that they can turn the usage of smartphones in class to their advantage for easier transmission of information into knowledge by asking the students, to seek a solution to a problem by the use of their phones.

\section{Evaluation}

A major problem to overcome in the learning process is the focus of the students on the evaluation and the grade they get rather than the learning itself.

The solutions shared by the teachers range from extreme clarity of the evaluation, as stated in the first lecture, to the diversification of the forms of evaluation. Some of the most interesting interview results follow. The lecturers shared forms of assessment that ranged from selfassessment of students and their choice of how to be evaluated to different forms of project activity in which students were evaluated not only for the achieved outcome but also for the different phases of the project: teamwork, adherence to deadlines, delegation of responsibilities, communication and leadership.

\section{Personal attitude}

In view of a growing lack of empathy in human relations, keeping the distance and at the same time the integration of students in a community with the teachers was the last important topic shared in the interviews.

The need for tutoring on one hand and on the other hand getting close just like a parent and kids have been pointed out to be especially important for the Generation Z. Building on a strong relationship with students - both hierarchical and supportive - was identified in many of the interviews.

Based on the information gathered and summarized in the above 5 problematic topics, we decided to create a training program for trainers. In the first phase, we relied on the information concerning the students directly received from the lecturers. In parallel, changing the survey system for students' satisfaction will provide us feedback about the effect of this training program over the next three semesters and whether it is in the right direction.

The Teacher Training Program will start in the spring semester of 2019. By the time of submitting the paper, the program is in draft form and at the time of the conference the first edition of the program will have been completed and the report issued. The first phase of the program will take the form of a seminar with six meetings, distributed evenly throughout the semester. A classical structure of a seminar will be used - moderator introducing the subject and one or two presenters and discussion in the end. In the second phase, it is intended to transform the seminars into workshops to accumulate sufficient information for creation of a standard to be adhered to by the lecturers. 
The topics for the seminars are as follows:

1. Presentation of a course (curriculum of course in an understandable language) - the subject is related to the need of the students to be explained at the beginning of the course why they study the specific discipline, what they will learn and how they will be able to use it.

2. Presentations, films, images and video lectures - the topic will focus on the student's need to be presented visual rather than textual information.

3. Case Studies, Simulations, Terrain, Games, Learning by Working - the topic will explore possible ways to use practical tasks in the learning process as well as involving the student's personal smart devices in the learning process.

4. Creating a Knowledge Necessity - the topic will look at how to awaken the perceived need to transform information into knowledge and the ability to reproduce what has been learned.

5. Evaluation - freedom and boundary - the subject will focus on innovative ways of evaluation.

6. Attitude, distance, trust, dialogue, empathy - the theme will focus on soft skills and empathy between the teacher and the students; the emphasis will be on how teachers are to be tutoring their students and at the same time bringing them to the academic community while keeping the distance between themselves and their learners.

\section{Conclusion}

The Generation $\mathrm{Z}$ is a generation that does not know the world before the Internet. This qualitatively different condition made Marc Prenski in 2001 call this generation digitally born, and the rest digital immigrants. At the same time, Prenski discusses how teachers should not train with yesterday and even today methods, but with tomorrows. The options for this are two, the students to learn our language or the opposite. The answer will predetermine the future of higher and university education. And as if this question has already been answered we must learn to communicate with Generation $\mathrm{Z}$ on its own language.

Universities face a complex and multifaceted situation where they must simultaneously make a number of transformations, often revolutionary, in teaching, appraising, and communicating, while at the same time preserving their mission in places where elite minds are grown and create knowledge. A positive side is that almost everything that needs to be done already exists and happens in one form or another. The challenge is how conservative institutions and minds, such as those of most university people, can accept this externality as their own. 


\section{References}

Campbell, A. J., Cumming, S. R., \& Hughes, I. (2006). Internet use by the socially fearful: Addiction or therapy? Cyberpsychology and Behavior, 9(1), 69-81.

Junco, R., \& Mastrodicasa, J. (2007). Connecting to the Net.Generation: What higher education professionals need to know about today's students. NASPA. ISBN 978-0-931654-48-0.

Prensky, M. (2001). Digital Natives, Digital Immigrants Part 1. On the Horizon, 9, 1-6. doi: $10.1108 / 10748120110424816$.

Toussaint, B. (1978). Qu'est-ce la séminiologie? Privat. 